\title{
Pivotal roles of artificial oxygen vacancies in enhancing photocatalytic activity and selectivity on $\mathrm{Bi}_{2} \mathrm{O}_{2} \mathrm{CO}_{3}$ nanosheets
}

\author{
Hongjing Liu a, Peng Chen c, Xiaoya Yuan d, Yuxin Zhang e, Hongwei Huang f, Li'ao Wang a, \\ Fan Dong $\mathrm{b}^{*}$ \\ a State Kay Laboratory of Coal Mine Disaster Dynamics and Control, College of Resource and Environmental Science, Chongqing University, Chongqing \\ 400044, China \\ ${ }^{\mathrm{b}}$ Research Center for Environmental Science \& Technology, Institute of Fundamental and Frontier Sciences, University of Electronic Science and \\ Technology of China, Chengdu 611731, Sichuan, China \\ c Chongqing Key Laboratory of Catalysis and New Environmental Materials, College of Environment and Resources, Chongqing Technology and Business \\ University, Chongqing 400067, China \\ d College of Materials Science and Engineering, Chongqing Jiaotong University, Chongqing 400074, China \\ e State Key Laboratory of Mechanical Transmissions, College of Materials Science and Engineering, Chongqing University, Chongqing 400044, China \\ f National Laboratory of Mineral Materials, School of Materials Science and Technology, China University of Geosciences, Beijing 100083, China
}

\section{A R T I C L E I N F O}

\section{Article history:}

Received 12 December 2018

Accepted 14 December 2018

Published 5 May 2019

\section{Keywords:}

Bismuth carbonate

Oxygen vacancy

Visible light photocatalysis

Reactant activation

Photocatalysis mechanism

\begin{abstract}
A B S T R A C T
There is an increasing interest in bismuth carbonate $\left(\mathrm{Bi}_{2} \mathrm{O}_{2} \mathrm{CO}_{3}, \mathrm{BOC}\right)$ as a semiconductor photocatalyst. However, pure BOC strongly absorbs ultraviolet light, which drives a high recombination rate of charge carriers and thereby limits the overall photocatalysis efficiency. In this work, artificial oxygen vacancies (OV) were introduced into BOC (OV-BOC) to broaden the optical absorption range, increase the charge separation efficiency, and activate the reactants. The photocatalytic removal ratio of NO was increased significantly from $10.0 \%$ for pure BOC to $50.2 \%$ for OV-BOC because of the multiple roles played by the oxygen vacancies. These results imply that oxygen vacancies can facilitate the electron exchange between intermediates and the surface oxygen vacancies in OV-BOC, making them more easily destroyed by active radicals. In situ DRIFTS spectra in combination with electron spin resonance spectra and density functional theory calculations enabled unraveling of the conversion pathway for the photocatalytic NO oxidation on OV-BOC. It was found that oxygen vacancies could increase the production of active radicals and promote the transformation of NO into target products instead of toxic byproducts $\left(\mathrm{NO}_{2}\right)$, thus the selectivity is significantly enhanced. This work provides a new strategy for enhancing photocatalytic activity and selectivity.
\end{abstract}

(C) 2019, Dalian Institute of Chemical Physics, Chinese Academy of Sciences. Published by Elsevier B.V. All rights reserved.

\section{Introduction}

Photocatalysis technology uses solar energy to transform toxic and harmful substances into non-toxic substances through a series of oxidation-reduction reactions. It has been widely investigated for its potential in applications for treat-

\footnotetext{
* Corresponding author. Tel/Fax: +86-23-62769785; E-mail: dfctbu@126.com

This work was supported by the National Key R\&D Program of China (2016YFC02047), the National Natural Science Foundation of China (21822601, 21777011, and 21501016), the Graduate Research and Innovation Foundation of Chongqing (CYS18019), the Innovative Research Team of Chongqing (CXTDG201602014), the Natural Science Foundation of Chongqing (cstc2017jcyjBX0052), and the National Special Supporting National Plan for High-Level. The authors also acknowledge the AM-HPC in Suzhou, China for computational support.

DOI: S1872-2067(19)63279-1 | http://www.sciencedirect.com/science/journal/18722067 | Chin. J. Catal., Vol. 40, No. 5, May 2019
} 
ment of environmental pollutants, such as formaldehyde, toluene, oxalic acid, carbon dioxide, and nitrogen oxide [1-8]. There are three primary processes in photocatalytic reactions: (1) the generation of electron/hole pairs under light illumination; (2) the separation and migration of photo-stimulated electrons and holes; and (3) the photocatalytic redox reaction [9,10]. Currently, the overall efficiency of photocatalytic conversion of typical photocatalysts is still unsatisfactory. Therefore, various strategies have been applied to improve photocatalytic performance, for instance, by doping with impurity atoms, constructing vacancies, designing heterostructures, and so on [11-13].

$\mathrm{Bi}_{2} \mathrm{O}_{2} \mathrm{CO}_{3}$ (BOC) is a typical "Aurivillius" phase in which a $\left[\mathrm{Bi}_{2} \mathrm{O}_{2}\right]^{2+}$ layer and a $\left[\mathrm{CO}_{3}\right]^{2-}$ layer are integrated in an orthogonal manner, forming a two-dimensional structure [14]. The highly asymmetric internal structure of BOC is obviously beneficial for the formation of special planar BOC sheets [15,16], and BOC is a candidate suitable for use in a variety of fields, such as healthcare, photocatalysis, humidity sensing, nonlinear optical applications, and energy storage in supercapacitors. Recently, the photocatalytic properties of BOC have drawn increased attention because BOC can be used as a semiconductor photocatalyst to efficiently degrade dye wastewater [17] and remove gaseous acetaldehyde [18]. However, pristine BOC strongly absorbs UV, which drives a high charge-carrier recombination rate, thereby limiting photocatalytic efficiency [19].

Recently, it was reported that photocatalytic nanomaterials can be enhanced by adding oxygen vacancies [20,21]. In particular, surface oxygen vacancies could capture light-generated charges and transfer the captured electrons to the adsorbed species of catalyst, thus effectively preventing charge-carrier recombination. This would enhance the photocatalytic activity $[22,23]$. On the other hand, by the introduction of surface oxygen vacancies, the optical response range could be expanded by lifting up the top of the valence band; thus reducing the band gap [24]. However, the potential mechanisms of the oxygen-vacancies-dependent photocatalytic activity and selectivity are not fully understood. Thus, constructing oxygen vacancies on the surface of BOC to enhance its photocatalytic performance, and understanding fully the surface oxygen-vacancies-dependent photocatalytic activity and selectivity are essential for developing a novel photocatalyst.

In this study, we introduced oxygen vacancies on the surface of pristine BOC by adding $\mathrm{NaBH}_{4}$ (the product is labeled OV-BOC) and found that the addition of $\mathrm{NaBH}_{4}$ could change the surface structure of BOC and produce more oxygen vacancies as reaction sites for activating reactants. The oxygen vacancies in BOC could decrease the forbidden band width, promote charge transfer and improve the photocatalytic performance of visible light. The results of electron spin resonance (ESR) spectra and density functional theory (DFT) calculation indicate that activation of $\mathrm{O}_{2}$ and $\mathrm{H}_{2} \mathrm{O}$ molecules is highly promoted and thus more reactive oxygen species (ROS) would be generated to participate in photocatalytic reactions. Therefore, the efficiency of NO removal should be greatly enhanced. More interestingly, the evolution process of intermediate products in the process of photocatalytic NO oxidation was monitored dynamically using in situ DRIFTS. The results imply that oxygen vacancies can also facilitate electron exchange between the intermediates and the surface OV in OV-BOC, leading them to be destroyed more easily by the active radicals. This is also beneficial for the transformation of NO into target products rather than toxic byproducts, so that the selectivity can be enormously promoted by the pathway: $\mathrm{NO} \rightarrow \mathrm{NO}_{2} \rightarrow \mathrm{NO}_{3}{ }^{-}$. This work should provide new insights into the understanding of oxygen vacancies in reactant activation and in photocatalytic selectivity.

\section{Experimental}

\subsection{Materials and fabrication}

All chemicals used in this work were analytical grade and were used without further treatment. In a typical synthesis, a certain amount of $\mathrm{Bi}\left(\mathrm{NO}_{3}\right)_{3} \cdot 5 \mathrm{H}_{2} \mathrm{O}(1.21 \mathrm{~g})$ was dissolved in 100 $\mathrm{mL}$ of nitric acid solution ( $0.9 \mathrm{~mol} / \mathrm{L})$ and stirred for $30 \mathrm{~min}$. Then, $15 \mathrm{~mL}$ of concentrated ammonia solution $(25.0 \%)$ was added and a white precipitate was produced and stirred for 5 min. $\mathrm{A} \mathrm{CO}_{2}$ gas stream $(1.0 \mathrm{~L} / \mathrm{min})$ was introduced into the above suspension, which was stirred for $30 \mathrm{~min}$. After the gas stream was stopped, the resulting precipitate was filtered, washed with water and ethanol four times, and then dried at 60 ${ }^{\circ} \mathrm{C}$ to get the final $\mathrm{Bi}_{2} \mathrm{O}_{2} \mathrm{CO}_{3}$ with no further treatment. The resulting product was labeled BOC.

In order to introduce the oxygen vacancies into the $\mathrm{Bi}_{2} \mathrm{O}_{2} \mathrm{CO}_{3}$, appropriate amounts of PVP $(1.0 \mathrm{~g})$ and $\mathrm{BOC}(2$ mmol) were mixed with $100 \mathrm{~mL}$ of $\mathrm{H}_{2} \mathrm{O}$ in a $250 \mathrm{~mL}$ beaker and stirred for $20 \mathrm{~min}$. Next, $30 \mathrm{~mL}$ of $70 \mathrm{mmol} / \mathrm{L} \mathrm{NaBH}_{4}$ solution was prepared and gradually poured into the beaker, stirring for $1 \mathrm{~h}$ and aged for $1 \mathrm{~h}$. The resulting precipitate was filtered, washed with water and ethanol four times and dried at $40{ }^{\circ} \mathrm{C}$ to get the final product, labeled OV-BOC. To illustrate the formation mechanism of OV-BOC via $\mathrm{NaBH}_{4}$ treatment, a surface molecular structure model and corresponding chemical equation are provided in Scheme S1 (Supporting Information).

\subsection{Characterization}

The crystal phases of the product samples were analyzed using X-ray diffraction (XRD) with $\mathrm{Cu} K_{\alpha}$ radiation (model D/max RA, Rigaku Co., Japan). X-ray photoelectron spectroscopy (XPS) with Al $K_{\alpha}$ X-rays (Thermo ESCALAB 250, U.S.A.) was used to investigate the surface properties. The morphology and structure of the samples were examined using scanning electron microscopy (SEM, model JSM-6490, JEOL, Japan) and transmission electron microscopy (TEM, JEM-2010, Japan). The UV-vis diffuse-reflectance spectrometry (UV-vis DRS) spectra were obtained for the dry-pressed disk samples using a scanning UV-vis spectrophotometer (UV2550, Shimadzu, Japan) equipped with an integrating sphere assembly, and using $100 \%$ $\mathrm{BaSO}_{4}$ as the reflectance sample. Photoluminescence (PL) studies (F-7000, HITACHI, Japan) were conducted to investigate the optical properties of the samples. Electron spin reso- 
nance (ESR) of radicals spin-trapped by 5,5-dimethyl-1-pyrroline N-oxide (DMPO) was recorded on a JES FA200 spectrometer. Samples for ESR measurement were prepared by mixing the samples in a $40 \mathrm{mmol} / \mathrm{L}$ DMPO solution tank (aqueous dispersion for DMPO-•OH and methanol dispersion for DMPO- $\bullet \mathrm{O}_{2}^{-}$) and irradiating with visible light. Electron paramagnetic resonance (EPR) measurements were carried out on a Bruker ESP 500 spectrometer.

\subsection{Evaluation of visible-light photocatalytic activity}

The photocatalytic activity was investigated using the removal ratio of NO at parts per billion proportions in a continuous-flow reactor at ambient temperature. The volume of the rectangular reactor, which was made of polymeric glass and covered with Saint-Glass, was $4.5 \mathrm{~L}(30 \mathrm{~cm} \times 15 \mathrm{~cm} \times 10 \mathrm{~cm})$. A $150 \mathrm{~W}$ commercial tungsten halogen lamp was placed vertically outside the reactor. A UV cutoff filter $(420 \mathrm{~nm})$ was utilized to remove the UV light in the light beam. For each test, $0.20 \mathrm{~g}$ of the prepared sample was dispersed in distilled water $(50 \mathrm{~mL})$ in a beaker via ultrasonic treatment for dispersion and then coated onto two glass dishes $(12.0 \mathrm{~cm}$ diameter). Each coated dish was dried at $60^{\circ} \mathrm{C}$ to remove the water and then cooled to room temperature before the test.

The NO gas was obtained from a compressed gas cylinder at a concentration of $100 \mathrm{ppm}$; then the NO was diluted to about $600 \mathrm{ppb}$ by the air stream. The desired relative humidity level of the NO flow was kept at $50 \%$ by passing the zero air streams through a humidification chamber. The gas streams were premixed completely using a gas blender, and the flow rates of the air stream and NO were maintained at $2.4 \mathrm{~L} / \mathrm{min}$ and 24 $\mathrm{mL} / \mathrm{min}$, respectively, by a mass flow controller. After the adsorption-desorption equilibrium was achieved, the lamp was turned on. The concentration of NO was continuously measured using a $\mathrm{NO}_{x}$ analyzer (Thermo Environmental Instruments Inc., Model 42c-TL). The removal ratio ( $\eta$ ) of NO was calculated as $\eta=\left(1-C / C_{0}\right) \times 100 \%$, where $C$ and $C_{0}$ are the concentrations of NO in the outlet steam and the feed stream, respectively. The generation ratio $(\varphi)$ of $\mathrm{NO}_{2}$ was calculated as $\varphi=\mathrm{C}_{1} /\left(C_{0}-C\right) \times$ $100 \%$, where $\mathrm{C}_{1}$ is the concentration of $\mathrm{NO}_{2}$ in the outlet steam.

\subsection{In situ DRIFTS study on photocatalytic NO oxidation process}

In situ DRIFTS measurements were conducted using the Tensor II FT-IR spectrometer (Bruker) equipped with an in situ diffuse reflectance cell (Harrick). Photocatalysts were put into the reaction cell. First, the He gas $(100 \mathrm{~mL} / \mathrm{min})$ was used to remove the residual hydrocarbons, $\mathrm{H}_{2} \mathrm{O}$, and $\mathrm{CO}_{2}$ at $300{ }^{\circ} \mathrm{C}$. The real-time FT-IR spectrum after ventilation was utilized as the background. Then, the reaction mixtures $(50 \mathrm{~mL} / \mathrm{min} \mathrm{NO}, 50$ $\mathrm{mL} / \mathrm{min}_{2}$ ) were introduced into the cell. The NO adsorption to the catalysts was carried out for $20 \mathrm{~min}$. Next, photocatalysts were illuminated using a visible light source (MUA-210) for $1 \mathrm{~h}$. The real-time FT-IR spectra were detected every eight minutes. Meanwhile the gas fluxes were kept the same $(50 \mathrm{~mL} / \mathrm{min}$ NO, $50 \mathrm{~mL} / \mathrm{min} \mathrm{O}_{2}$ ). Finally, FT-IR spectra were recorded every two minutes with the same gas fluxes after turning off the light. The IR scanning range was 4000-600 $\mathrm{cm}^{-1}$. The intervals $2250-2000 \mathrm{~cm}^{-1}$ and $1120-840 \mathrm{~cm}^{-1}$ were analyzed to present the photocatalytic oxidation process happening on the catalysts.

\subsection{DFT calculations}

Spin-polarized DFT-D2 calculations were conducted using the "Vienna ab initio simulation package" (VASP5.4), applying a generalized gradient correlation functional [25]. A plane-wave basis set with cut-off energy $450 \mathrm{eV}$ within the framework of the projector-augmented wave method was employed [26]. The Gaussian smearing width was set to $0.2 \mathrm{eV}$. The Brillouin zone was sampled with a $3 \times 3 \times 1$ Monkhorst Pack grid. All atoms were converged to $0.01 \mathrm{eV} \AA^{-1}$. Hybrid functionals based on the Heyd-Scuseria-Ernzerhof (HSE06) method [27] were applied to estimate the exact band structures. The adsorption energy $\left(E_{\text {ads }}\right)$ is defined as

$E_{\text {ads }}=E_{\text {tot }}-\left(E_{\mathrm{s}}+E_{\mathrm{mol}}\right)$

where $E_{\mathrm{tot}}, E_{\mathrm{s}}$, and $E_{\mathrm{mol}}$ depict the total energy of the adsorption complex, the samples (pure BOC or OV-BOC), and the isolated molecule, respectively.

We established two models of oxygen vacancy (OV) to find the optimal one (Table 1). Two models of OV-BOC were used for comparison of the total energy $\left(E_{\mathrm{tot}}\right)$ of the different $\mathrm{OV}$ positions in BOC. The DFT results show that the total energy of Position $2(-583.72619 \mathrm{eV})$ is lower than the total energy of Position $1(-580.27379 \mathrm{eV})$, which suggests that Position 2 is more stable. Then, we chose the model of Position 2 to study the effects of oxygen vacancy in BOC.

\section{Results and discussion}

\subsection{Crystal structure, surface structure, and oxygen vacancies}

The pristine BOC and OV-BOC samples were characterized by XRD patterns in Fig. 1a. The peaks of BOC are in accordance with typical tetragonal BOC (JCPDS card No. 41-4188) and no

Table 1

Details of three positions of oxygen vacancy and calculated total energy. The OVs in Position 1 and Position 2 are located in the $\mathrm{CO}_{3}{ }^{2-}$ group and $[\mathrm{BiO}]^{+}$layer, respectively.

Position



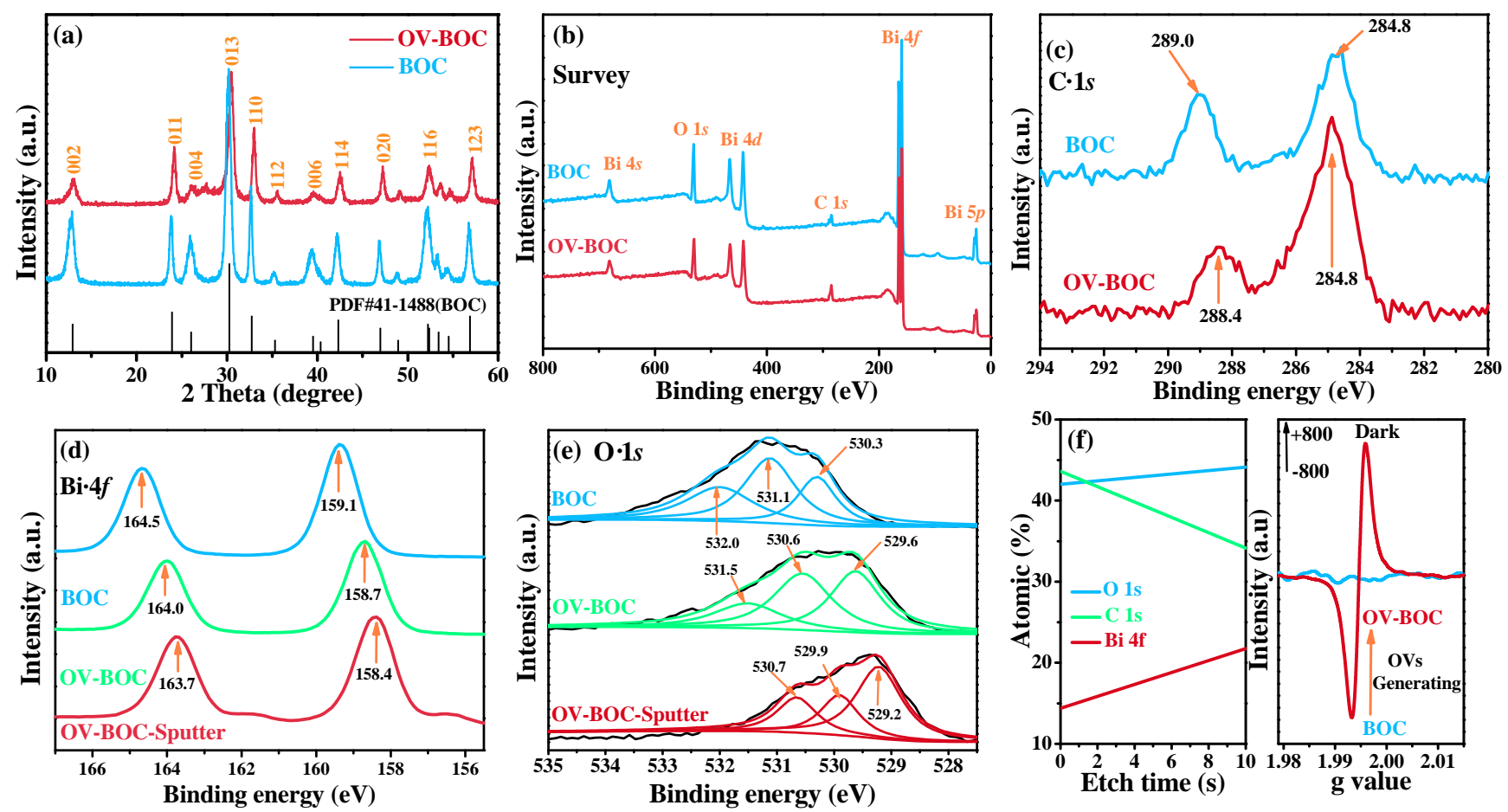

Fig. 1. XRD patterns of the photocatalytic materials (a); XPS spectra of the peaks of the four constituent elements survey scan (b), C- $1 s$ (c), Bi-4f (d), and $0-1 s$ (e); Element content survey of 10 s' etching and EPR spectra of OV-BOC (f).

other peaks appeared, indicating the high purity of the as-prepared $\mathrm{Bi}_{2} \mathrm{O}_{2} \mathrm{CO}_{3}$. Notably, the XRD pattern of the BOC sample shows a preferential exposed $\{001\}$ crystallographic plane supported by the intensified (002), (004), and (006) peaks [28]. In addition, the main peaks of OV-BOC are nearly identical to those of BOC, but the intensities of the peaks are obviously lower, demonstrating that the crystallinity of BOC is reduced after creation of oxygen vacancies on the surface.

The XPS survey spectra of both samples showed that peaks of the three elements Bi- $4 f, 0-1 s$, and C- $1 s$ can all be detected (Fig. 1b). The high resolution C-1s spectrum of BOC (Fig. 1c) reveals two peaks at 289.0 and $284.8 \mathrm{eV}$, which are assigned to the $\mathrm{C}-\mathrm{O}$ bond and adventitious hydrocarbon, respectively [29]. The two apparent characteristic peaks for Bi-4f located at 159.1 and $164.5 \mathrm{eV}$ are attributed to Bi- $4 f-7 / 2$ and Bi- $4 f-5 / 2$ in BOC (Fig. 1d) [30,31]. The high resolution XPS spectra of Bi- $4 f$ in OV-BOC and OV-BOC-Sputter (after the $20 \mathrm{~nm}$ sputtering) in Fig. $1 \mathrm{c}$ show that the $\mathrm{Bi}-4 f-7 / 2$ and $\mathrm{Bi}-4 f-5 / 2$ peaks move in the direction of lower binding energy in comparison to those of BOC. Moreover, the peaks of 0-1s at 530.3, 531.1, and $532 \mathrm{eV}$ of OV-BOC and OV-BOC-Sputter also shifted to lower binding energy compared to those of BOC (Fig. 1e) [32,33]. The shifting of $\mathrm{Bi}-4 f$ and $0-1 s$ should be ascribed to the existence of the oxygen vacancies, which made it easier to enrich electrons and transmit electrons to the $\mathrm{Bi}$ and $\mathrm{O}$ atoms in the $\left[\mathrm{Bi}_{2} \mathrm{O}_{2}\right]^{2+}$ layers. Furthermore, the etching spectra of the OV-BOC surface (Fig. 1f) reveal less 0 -atom exposure on the surface, which may also suggest the formation of oxygen vacancies on OV-BOC.

To confirm further the successful creation of oxygen vacancies in BOC via the addition of $\mathrm{NaBH}_{4}$, low-temperature sol- id-state electron paramagnetic resonance (EPR), a sensitive and efficient technique, was applied to detect the oxygen vacancies. As shown in Fig. 1f, OV-BOC shows the obvious paramagnetic resonance signal of oxygen vacancies at a $g$ value of 1.995 in the dark, in contrast to that of pure BOC. This provides solid evidence for the existence of oxygen vacancies in OV-BOC [34]. (a)

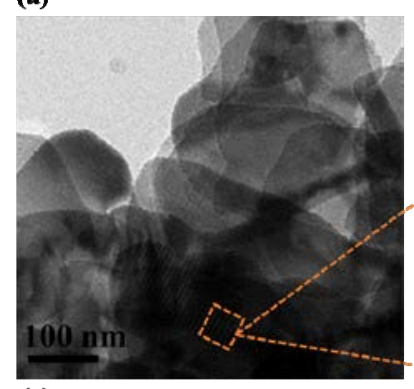

(c)

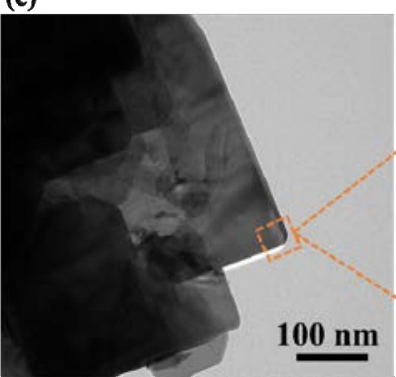

(b)

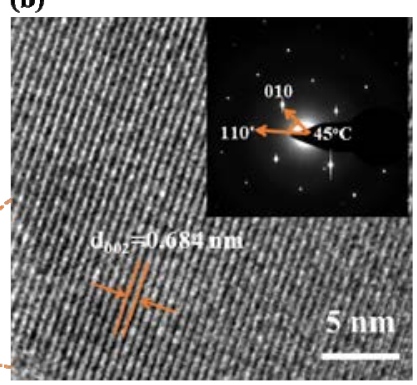

(d)

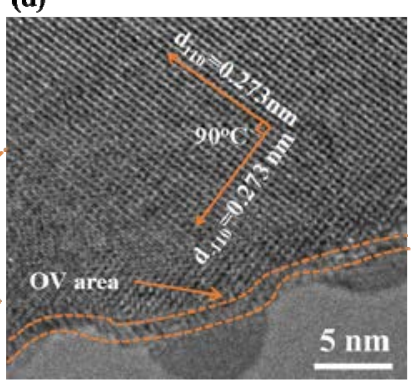

Fig. 2. TEM image of BOC (a); HRTEM image of BOC (b); TEM image of OV-BOC (c); HRTEM image of OV-BOC (d). 


\subsection{Morphology, microstructure, and exposing facets}

SEM and TEM were employed to survey the morphology and micro-structure of pristine BOC and OV-BOC (Fig. S1 and Fig. 2). Based on the SEM observations (Fig. S1), it can be observed that both BOC and OV-BOC consist of large scale nanoplates that might be formed owing to the internal layered crystal structure of $\mathrm{Bi}_{2} \mathrm{O}_{2} \mathrm{CO}_{3}$ with weak Van der Waals interactions along the [001] direction [35]. Furthermore, TEM images of BOC and OV-BOC further confirm the nanoplate morphology in Fig. 2a and 2c, respectively. Interestingly, the OV-BOC reveals obviously the regular contour of the nanosheets. The HRTEM images of pristine BOC (Fig. 2b) show that the fringe spacing of $0.68 \mathrm{~nm}$ could match well the (002) atomic planes of tetragonal $\mathrm{Bi}_{2} \mathrm{O}_{2} \mathrm{CO}_{3}$, consistent with the results from the XRD patterns (Fig. 1a). The single-crystal characteristics and the corresponding $\{001\}$ plane exposure of BOC are demonstrated by the selected-area electron diffraction (SAED) pattern in Fig. $2 b$. The angle between the typical planes are in line with theoretical values [36]. The HRTEM image (Fig. 2d) exhibits fringe spacing of $0.273 \mathrm{~nm}$ and an angle of $90^{\circ}$, which well match the (110) atomic planes of tetragonal $\mathrm{Bi}_{2} \mathrm{O}_{2} \mathrm{CO}_{3}$, consistent with the results from XRD patterns (Fig. 1a). On the basis of these results, the wide surface of OV-BOC can be unambiguously identi- fied as the $\{001\}$ crystallographic plane $[37,38]$. Moreover, it is noteworthy that the edge of the OV-BOC nanosheet was somewhat damaged, which may demonstrate the existence of oxygen vacancies on the surface of OV-BOC [39].

\subsection{Photocatalytic activity, light absorption, and charge separation}

The photocatalytic activity of the prepared samples was evaluated via photo-oxidation of NO in a continuous-flow reactor under visible light irradiation. As shown in Fig. 3a, the photocatalytic performance of OV-BOC (NO removal ratio of $50.2 \%$ ) far exceeds that of pristine BOC (about 10.0\%), which indicates that the construction of oxygen vacancies could effectively enhance the photocatalytic performance of BOC. For photocatalytic NO oxidation removal, the generation of toxic $\mathrm{NO}_{2}$ intermediates should be controlled. Notably, $\mathrm{NO}_{2}$ is almost controlled for OV-BOC, in comparison with the high fraction of $\mathrm{NO}_{2}$ generation (roughly 80.9\%). This indicates that oxygen vacancies could promote the transformation of NO into target products instead of toxic byproducts $\left(\mathrm{NO}_{2}\right)$. To detect further the final products after photocatalytic reaction, we washed the used catalyst after $8 \mathrm{~h}$ reaction using $100 \mathrm{~mL}$ of distilled water. The nitrate in the resultant solution was then analyzed via ion
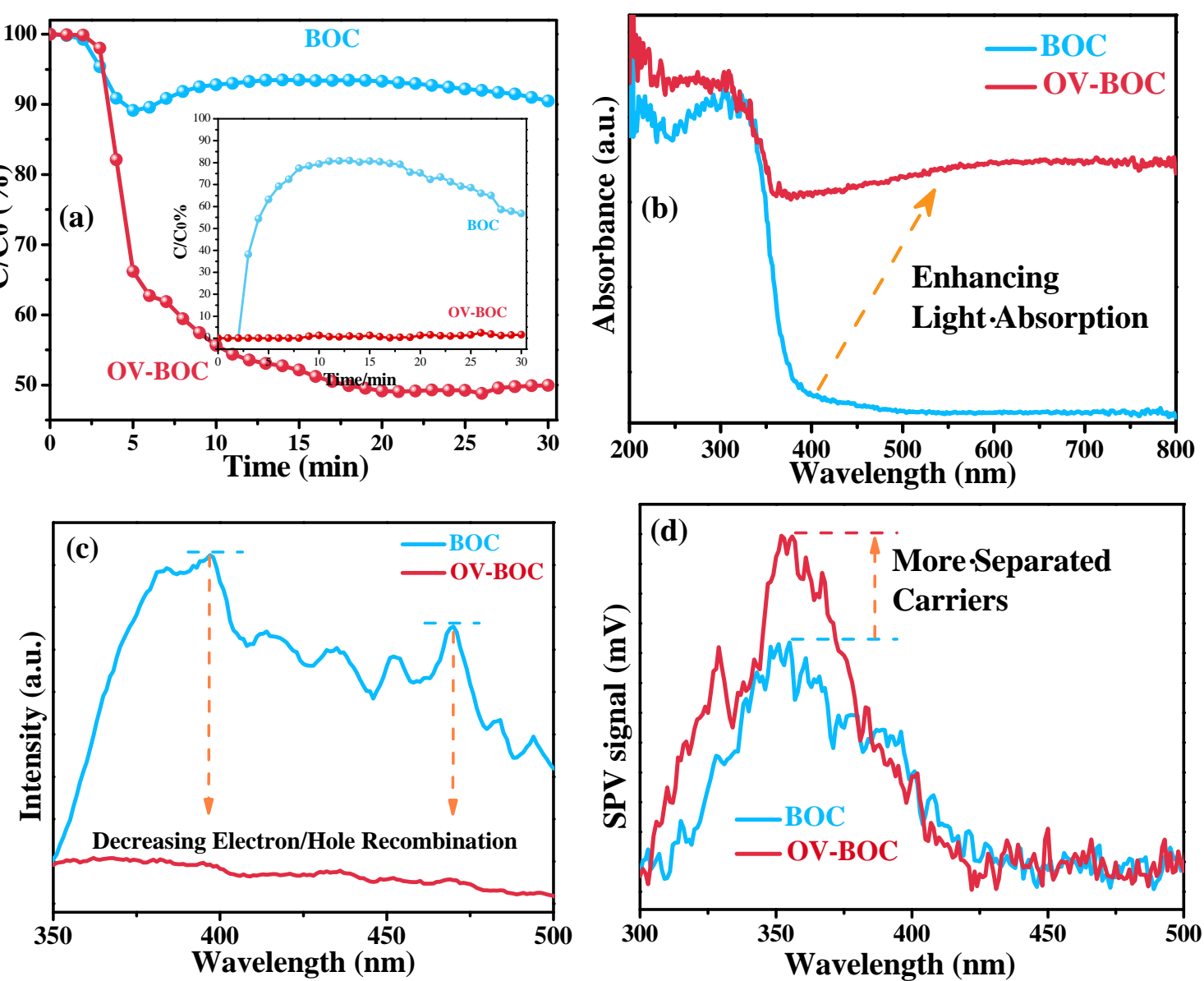

Fig. 3. Photocatalytic activity for $\mathrm{NO}$ removal and $\mathrm{NO}_{2}$ generation rate (a); UV-vis spectra (b); PL spectra of two as-prepared samples (c); Photovoltage spectra (d). 
chromatography. The result reveals that the concentration of nitrate is $5.57 \mathrm{~g} / \mathrm{L}$ ( $0.0089 \mathrm{~mol}$ nitrate in $100 \mathrm{~mL}$ water). Within $8 \mathrm{~h}, 0.0117 \mathrm{~mol}$ of NO was introduced into the reactor. Accordingly, the conversion ratio of $\mathrm{NO}$ to $\mathrm{NO}_{3}-$ was $76.1 \%$.

More specifically, the OV-BOC exhibits a broadened visible light response, as shown in the Fig. $3 \mathrm{~b}$, compared to that of pristine BOC. Moreover, both the photoluminescence (Fig. 3c) and photovoltage spectra (Fig. 3d) demonstrated the enhanced electron/hole separation efficiency of OV-BOC compared to that of pristine BOC. The forbidden band width $E_{\mathrm{g}}$ can be obtained by means of $(\alpha h v)^{1 / 2}$ of the BOC and OV-BOC samples [40]. The band gap of OV-BOC $(2.53 \mathrm{eV})$ is less than BOC $(3.15$ $\mathrm{eV}$ ), suggesting that the introduction of oxygen vacancies could reduce the band gap of BOC in Fig. S2a.

To probe further the change of band gap, the electrochemical Mott-Schottky measurements were used to obtain the energy-band potential of the samples (Fig. S2b). The positive slope of the $\mathrm{C}^{-2}-\mathrm{V}$ curves represents the n-type character of synthesized BOC and OV-BOC [41]. Meanwhile, the flat potential of OV-BOC and BOC obtained by extrapolation of the Mott-Schottky plot is roughly -0.79 and $-0.70 \mathrm{~V}$, respectively, versus the saturated calomel electrode (SCE). The latter is equivalent to -0.55 and $-0.46 \mathrm{~V}$, respectively, versus the normal hydrogen electrode (NHE). As far as we know, the flat band potential (quasi Fermi level) is $0.1 \mathrm{~V}$ lower than the conduction band minimum for n-type semiconductors [42]. Therefore, the conduction band (CB) minimum of OV-BOC and BOC is -0.65 and $-0.56 \mathrm{~V}$, respectively. The valence bands (VB) of OV-BOC and BOC were determined to be 1.88 and $2.59 \mathrm{~V}$, respectively.

To study further the durability of the OV during the photoreaction, we tested the photo-oxidation of NO over OV-BOC in the continuous-flow reactor under visible light irradiation for 8 h (labeled OV-BOC-8h). Note that the NO removal ratio decreased from $47.0 \%$ to $21.0 \%$ (Fig. S3a). This reduction was ascribed to the decreased number of oxygen vacancies under prolonged visible light illumination, and to the accumulation of nitrates $\left(\mathrm{NO}_{3}-\right)$ on the surface of the photocatalyst. The decreased visible-light response (Fig. S3b) and ESR signal (Fig. S3c) of OV-BOC-8h certify that the oxygen vacancies are partially consumed and thus lead to decreased photocatalytic activity. As shown in Fig. S3d-f, the peaks of Bi- $4 f-7 / 2$ and Bi-4f-5/2 of OV-BOC-8h shifted positively compared to the peaks of OV-BOC (Fig. S3d). This indicates that the oxygen vacancies have been partially consumed via reaction with $\mathrm{O}_{2}$.
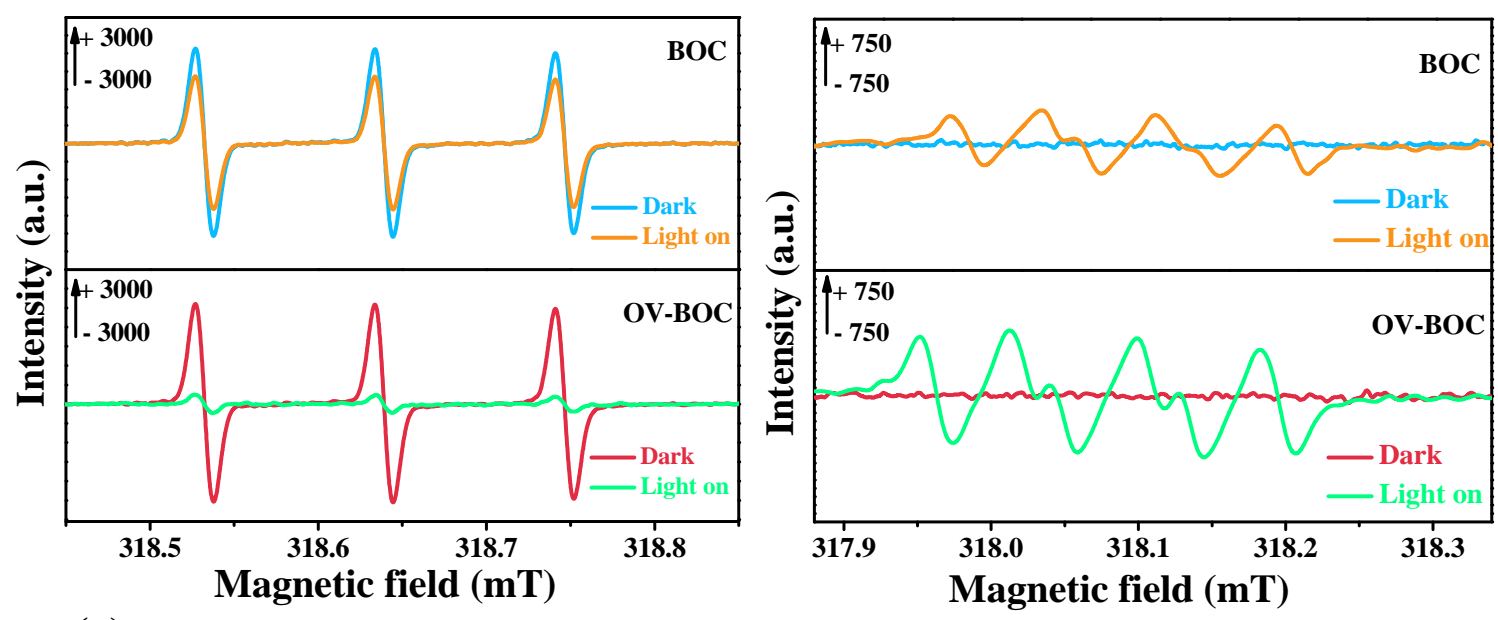

(c)

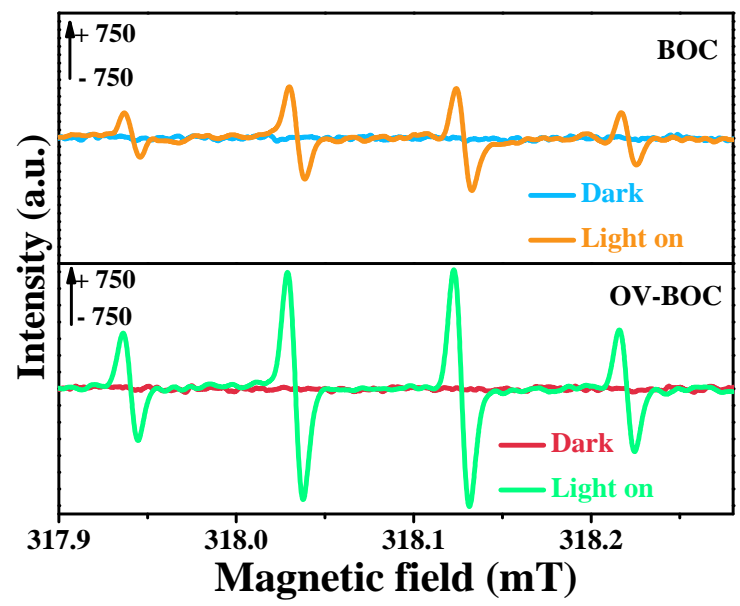

(d)

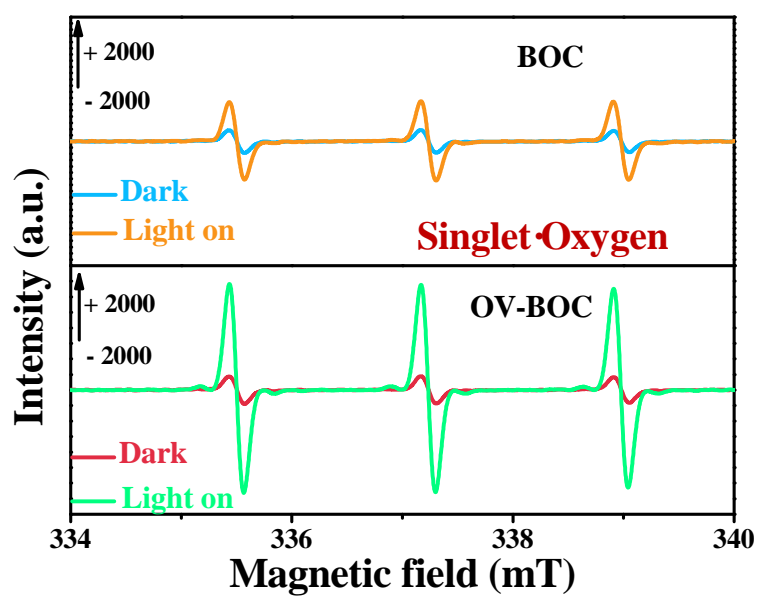

Fig. 4. DMPO ESR spectra in dark and under visible light $\left(\lambda \geq 420 \mathrm{~nm}\right.$ ) for $15 \mathrm{~min}$ in a methanol dispersion, for $\mathrm{e}^{-}(\mathrm{a}), \bullet_{2}{ }^{-}$(b), aqueous dispersion for $\bullet \mathrm{OH}(\mathrm{c})$, and singlet oxygen (d). 


\subsection{Generation of reactive oxygen species (ROS) from $\mathrm{O}_{2}$ and $\mathrm{H}_{2} \mathrm{O}$ activation}

The generation of active radicals is a prerequisite to initiation of the photo-oxidation reactions [43]. The reactive oxygen species (ROS) were detected via DMPO spin-trapping ESR measuring. The electron $\left(\mathrm{e}^{-}\right)$signal intensity of OV-BOC is obviously decreased under visible light illumination in comparison to that of pristine BOC in Fig. 4a, which indicates that the photo-generated electrons $\left(\mathrm{e}^{-}\right)$are consumed to activate reactants $\left(\mathrm{O}_{2}\right)$ and induce the generation of $\operatorname{ROS}\left(\bullet^{-}{ }^{-}\right)$. Apparently, the signals of super oxygen $\left(\bullet \mathrm{O}_{2}{ }^{-}\right)$, hydroxyl radicals $(\bullet \mathrm{OH})$, and singlet oxygen $\left({ }^{1} \mathrm{O}_{2}\right)$ were observed under visible light (Fig. $4 \mathrm{~b}-\mathrm{d}$ ) [44]. Interestingly, all the ROS signal intensities of OV-BOC vastly surpass those of BOC, which further demonstrates that oxygen vacancies can promote the transport of carriers and thus facilitate the generation of ROS. Moreover, the ESR signals of $\bullet_{2} \mathrm{O}^{-}$are weaker than those of $\bullet \mathrm{OH}$ and ${ }^{1} \mathrm{O}_{2}$, which may be attributed to the conversion of $\bullet_{2} \mathrm{O}_{2}$ following the pathway $\bullet \mathrm{O}_{2}^{-} \rightarrow \mathrm{O}_{2}$ (oxidation) or $\bullet \mathrm{O}_{2}^{-} \rightarrow \mathrm{H}_{2} \mathrm{O}_{2} \rightarrow \bullet \mathrm{OH}$ (reduction) $[45,46]$. The generation of $\bullet \mathrm{OH}$ on $\mathrm{OV}$-BOC follows a more direct way: $\mathrm{H}_{2} \mathrm{O} \rightarrow \bullet \mathrm{OH}$, in which the $\mathrm{H}_{2} \mathrm{O}$ is oxidized by the photo-generated holes $\left(\mathrm{h}^{+}\right)$, which is further certified via the results of the DFT method in Fig. 6 . In addition, the $\bullet \mathrm{OH}$ signal intensity of OV-BOC exceeds that of pristine BOC, which demonstrates that oxygen vacancies can drive the separation of electrons/holes, and thus stimulate the generation of $\bullet \mathrm{OH}$.

Hence, Fig. 5 illustrates the band structure and photocatalytic NO removal process on OV-BOC. It can be seen that the oxygen vacancies in OV-BOC could reduce the width of the band gap, increase the charge separation efficiency, and activate the reactants to generate abundant reactive oxygen species (ROS).

To understand better the generation of ROS from the activation of $\mathrm{O}_{2}$ and $\mathrm{H}_{2} \mathrm{O}$ by oxygen vacancies at the molecular level, DFT methods were utilized to simulate the adsorption activation of $\mathrm{O}_{2}$ and $\mathrm{H}_{2} \mathrm{O}$ on the oxygen vacancy sites. In Fig. 6, the yellow and blue regions represent electron depletion and accumulation in the charge difference distribution calculation,

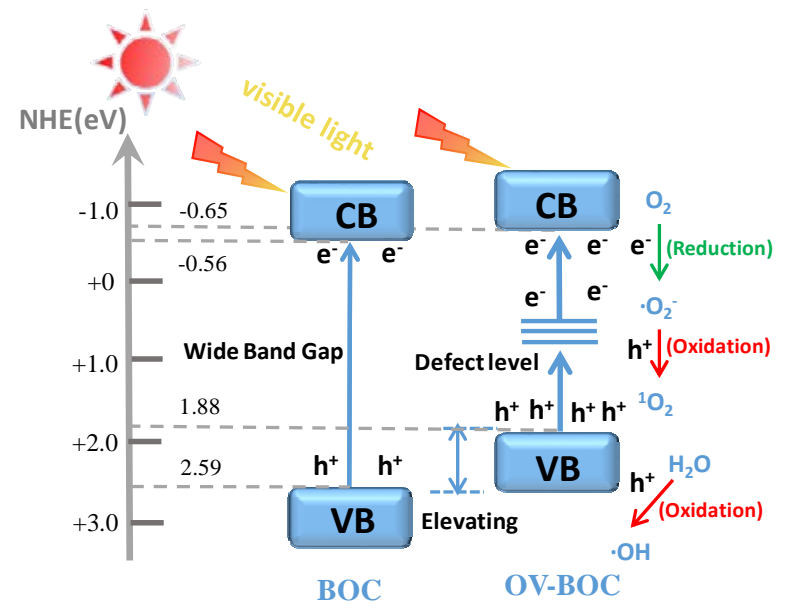

Fig. 5. Schematic illustration of the band structure and photocatalytic NO removal on OV-BOC.
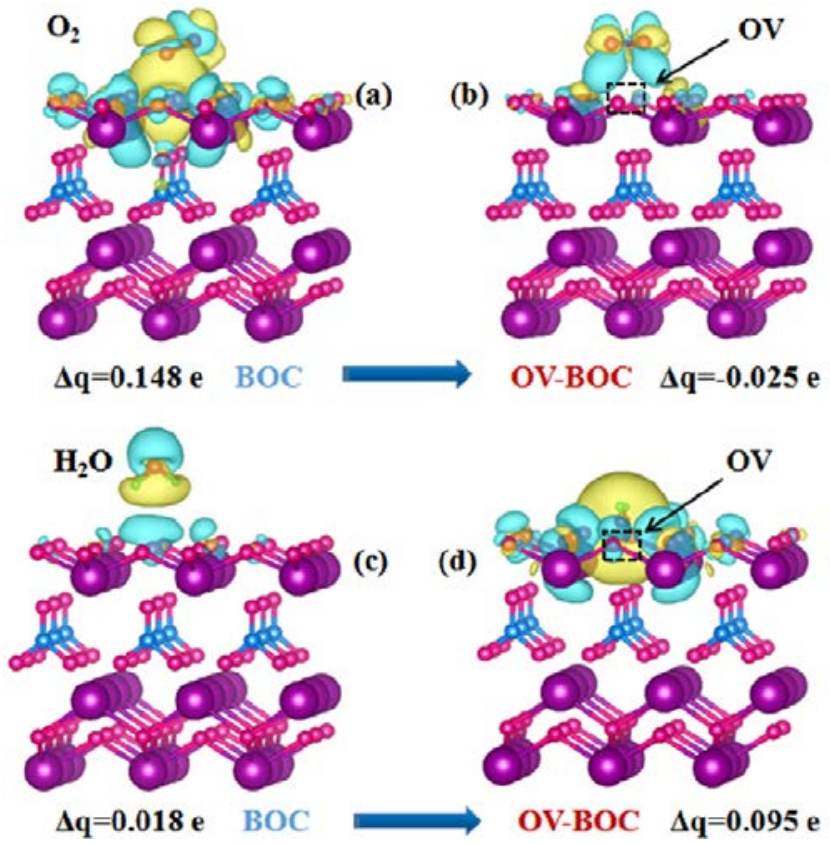

Fig. 6. Charge difference distribution of optimized $\mathrm{O}_{2}$ adsorption between $\mathrm{O}_{2}$ and BOC (a) and OV-BOC (b); Charge difference distribution of optimized $\mathrm{O}_{2}$ adsorption between $\mathrm{H}_{2} \mathrm{O}$ and BOC (c) and (d); The calculated Bader charge $(\Delta q)$ is the sum of Bader charges of several atoms of one $\mathrm{NO}$ or one $\mathrm{H}_{2} \mathrm{O}$ molecule and negative values of change in the Bader charge indicate the transfer of electrons from the $\mathrm{Bi}_{2} \mathrm{O}_{2} \mathrm{CO}_{3}$ surface to the adsorbed molecules.

respectively. The total charge $(\Delta q)$ of $\mathrm{O}_{2}$ and $\mathrm{H}_{2} \mathrm{O}$ molecules were calculated by the Bader method. As shown in Fig. 6a and $6 \mathrm{~b}$, the total charge $(\Delta q)$ of the adsorbed $\mathrm{O}_{2}$ molecule on the surface of OV-BOC is negative. The $\mathrm{O}_{2}$ molecule is mainly located in the blue region in comparison with that of BOC, which indicates that $\mathrm{O}_{2}$ molecules are inclined to capture electrons from oxygen vacancies in OV-BOC. This further certified the enhanced activation of $\mathrm{O}_{2}$ molecules via the oxygen vacancies. This corresponds to the increasing ESR signals of $\bullet \mathrm{O}_{2}{ }^{-}$and ${ }^{1} \mathrm{O}_{2}$ in Fig. $6 \mathrm{~b}$ and 6 d. Most importantly, the total charge $(\Delta q)$ of $\mathrm{H}_{2} \mathrm{O}$ is in the order: BOC (0.018 e) < OV-BOC (0.095 e). The $\mathrm{H}_{2} \mathrm{O}$ molecule on OV-BOC tends to occupy the oxygen vacancy sites and lose electrons to the surrounding atoms. This implies that the $\mathrm{H}_{2} \mathrm{O}$ molecules on OV-BOC are prone to lose electrons and inject them into the photogenerated holes $\left(\mathrm{h}^{+}\right)$around the oxygen vacancies. In this way, the $\mathrm{H}_{2} \mathrm{O}$ is activated to form $\bullet \mathrm{OH}$ radicals as follows: $\mathrm{H}_{2} \mathrm{O} \rightarrow \bullet \mathrm{OH}$, which is in accordance with the obviously enhanced ESR signals of $\bullet \mathrm{OH}$ in Fig. 6c. Therefore, the surface oxygen vacancies could not only function as activation sites for reactants, but could also prevent charge-carrier recombination.

\subsection{In situ DRIFTS investigation and photocatalysis selectivity}

The in situ DRIFTS, which can dynamically monitor the adsorbed reaction intermediates and products in a time sequence, was subsequently carried out to intuitively reveal the conversion pathways and reaction mechanism for photocatalytic NO oxidation (as shown in Fig. 7). Table S1 summarizes the possi- 
(a)

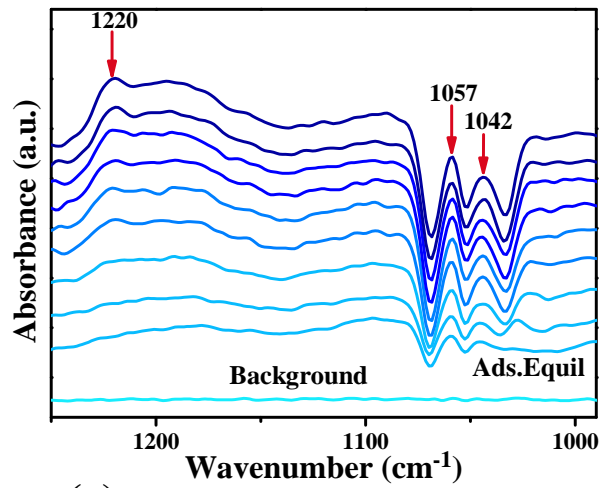

(c)

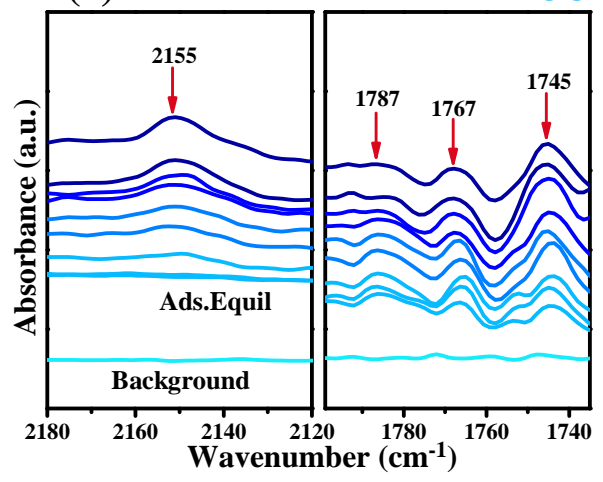

(b)

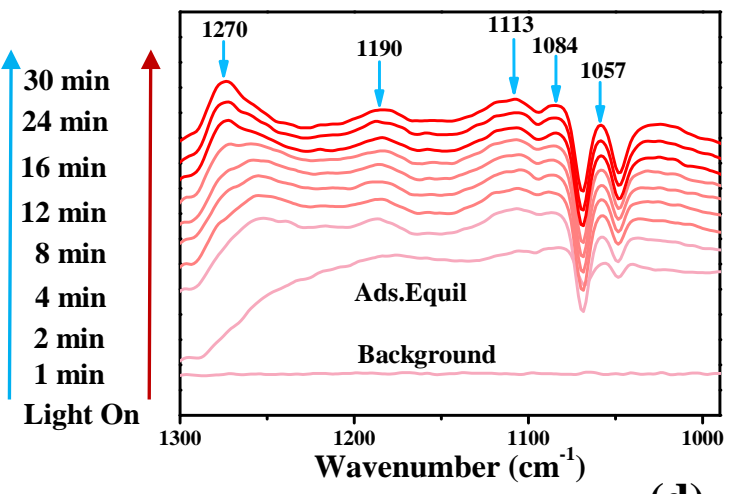

OV-BOC (d)

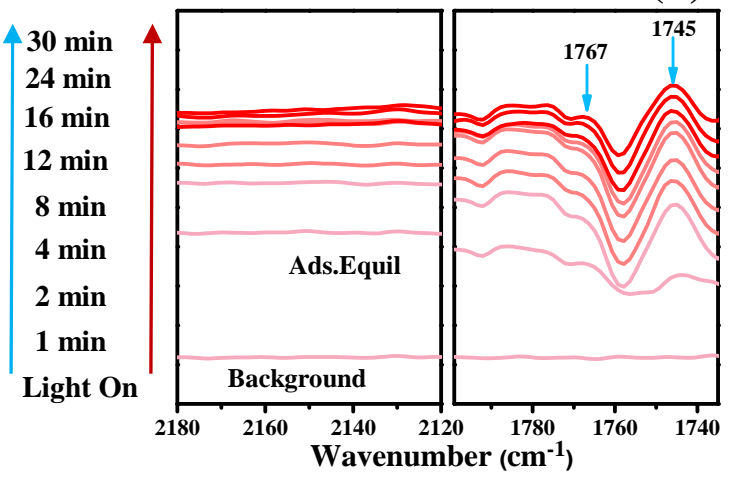

Fig. 7. In situ FT-IR spectra of the adsorption process of $\mathrm{NO}+\mathrm{O}_{2}$ for $\mathrm{BOC}(\mathrm{a})$ and (c); In situ FT-IR spectra of the adsorption process of $\mathrm{NO}+\mathrm{O}_{2}$ for OV-BOC (b) and (d).

ble assignments of the observed IR bands. The adsorption bands (NO) at 1767 and $1787 \mathrm{~cm}^{-1}$ can be observed in the adsorption equilibrium (Ads. Equil.) line on BOC in the dark (Fig. 7c) [47]. Simultaneously, the adsorption bands at 1057 and $1042 \mathrm{~cm}^{-1}$ appeared as well in the adsorption process (Fig. 7a) [48], which could be assigned to nitrates species. In addition, the intermediate $\left(\mathrm{NO}_{2}\right)$ band at $1745 \mathrm{~cm}^{-1}$ was also found in Fig. 7c [49,50]. Furthermore, as shown in the adsorption equilibrium (Ads. Equil.) line on OV-BOC (in Fig. 7b and 7d), we can see the adsorption bands at 1767 (NO), $1745\left(\mathrm{NO}_{2}\right)$, and 1057 (nitrates) $\mathrm{cm}^{-1}$.

Interestingly, the IR bands of BOC and OV-BOC gradually changed under visible light irradiation. As shown in the reaction process of BOC (Fig. 7a and 7c), the NO adsorption bands at 1787 and $1767 \mathrm{~cm}^{-1}$ weaken gradually after turning on the visible light. The new bands at 2155 and $1220 \mathrm{~cm}^{-1}[47,51]$ are observable and positively developed, and can be assigned to $\mathrm{NO}^{+}$and nitrates, respectively. Moreover, the intensity of the bands at $1745 \mathrm{~cm}^{-1}\left(\mathrm{NO}_{2}\right)$ also gradually increases under visible light irradiation. The transformation process on BOC $\left(\mathrm{NO} \rightarrow \mathrm{NO}_{2}\right)$ under visible light irradiation can be described by the following equations (1-8):

$$
\begin{gathered}
\mathrm{BOC}+\mathrm{h} v \rightarrow \mathrm{e}^{-}+\mathrm{h}^{+} \\
\mathrm{O}_{2}+\mathrm{e}^{-} \rightarrow \bullet \mathrm{O}_{2}^{-} \\
\bullet \mathrm{O}_{2}^{-}+\mathrm{h}^{+} \rightarrow{ }^{1} \mathrm{O}_{2} \\
\mathrm{H}_{2} \mathrm{O}+\mathrm{h}^{+} \rightarrow \bullet \mathrm{OH}+\mathrm{H}^{+} \\
\mathrm{NO}+\mathrm{h}^{+} \rightarrow \mathrm{NO}^{+}
\end{gathered}
$$

$$
\begin{gathered}
\mathrm{NO}^{+}+\bullet \cdot \mathrm{OH} \rightarrow \mathrm{NO}_{2}+\mathrm{H}^{+} \\
\mathrm{H}^{+}+3 \mathrm{NO}+2 \cdot \mathrm{O}_{2}^{-} \rightarrow 3 \mathrm{NO}_{2}+\mathrm{OH}^{-} \\
2 \mathrm{NO}+\mathrm{O}_{2} \rightarrow 2 \mathrm{NO}_{2}
\end{gathered}
$$

During the reaction process of OV-BOC (Fig. $7 \mathrm{~b}$ and $7 \mathrm{~d}$ ), the NO adsorption bands at $1767 \mathrm{~cm}^{-1}$ are negatively developed, but the development of the $\mathrm{NO}_{2}$ band at $1745 \mathrm{~cm}^{-1}$ and nitrate bands at $1270,1113,1084$, and $1057 \mathrm{~cm}^{-1}$ are positive [49]. In addition, the intensity of the band at $1190 \mathrm{~cm}^{-1}$ [50,52], assigned to NO-, can be observed in Fig. 7b. Furthermore, in contrast to the $\mathrm{BOC}$ reaction process, the intensity of the $\mathrm{NO}_{2}$ band of OV-BOC (Fig. 7d) increases faster, but weakens after $8 \mathrm{~min}$ and more new nitrate bands appear at 1270 [53], 1113, and $1084 \mathrm{~cm}^{-1}$. This might be closely related to the strong adsorption activation function of oxygen vacancies, and thus should promote the generation of ROS to participate in oxidation-reduction reactions, corresponding to the results of the DMPO spin-trapping ESR measuring (Fig. 4) and DFT methods (Fig. 6). The final transformations on OV-BOC $\left(\mathrm{NO} \rightarrow \mathrm{NO}_{2} \rightarrow \mathrm{NO}_{3}{ }^{-}\right.$) under visible light irradiation can be described by equations (9-17) [54].

$$
\begin{gathered}
\text { OV-BOC }+\mathrm{h} v \rightarrow \mathrm{e}^{-}+\mathrm{h}^{+} \\
\mathrm{O}_{2}+\mathrm{e}^{-} \rightarrow \bullet \mathrm{O}_{2}^{-} \\
\mathrm{NO}+\mathrm{e}^{-} \rightarrow \mathrm{NO}^{-} \\
\mathrm{H}_{2} \mathrm{O}+\mathrm{h}^{+} \rightarrow \bullet \mathrm{OH}+\mathrm{H}^{+} \\
\bullet \mathrm{O}_{2}^{-}+\mathrm{h}^{+} \rightarrow \mathrm{1}_{2} \\
\mathrm{NO}^{-}+\bullet \mathrm{O}_{2}^{-}+2 \mathrm{H}^{+} \rightarrow \mathrm{NO}_{2}+\mathrm{H}_{2} \mathrm{O} \\
2 \mathrm{NO}+{ }^{\mathrm{O}_{2}} \rightarrow 2 \mathrm{NO}_{2}
\end{gathered}
$$




$$
\begin{aligned}
& 2 \mathrm{NO}_{2}+2-\mathrm{O}_{2}^{-} \rightarrow 2 \mathrm{NO}_{3}{ }^{-}+\mathrm{O}_{2} \\
& \mathrm{NO}_{2}+\bullet \mathrm{OH} \rightarrow \mathrm{NO}_{3}{ }^{-}+\mathrm{H}^{+}
\end{aligned}
$$

Here, we analyze further the reasons for the different reaction processes on OV-BOC and BOC. First, NO transforms into the intermediate forms $\mathrm{NO}^{-}$and $\mathrm{NO}^{+}$on the surface of $\mathrm{OV}-\mathrm{BOC}$ and BOC, respectively, under illumination, which is closely related to the surface structure. The oxygen vacancies in OV-BOC can collect photo-generated electrons and then NO could capture the electrons and transform into NO-. The NO adsorbed on $\mathrm{BOC}$ gives electrons to fill in holes and thus $\mathrm{NO}$ is converted to $\mathrm{NO}^{+}$. Notably, the $\mathrm{N}-\mathrm{O}$ bond energy of several typical oxynitride and nitrogen oxygen ions follows the sequence $\mathrm{NO}^{+}>\mathrm{NO}>\mathrm{NO}^{-}$ according to the molecular orbital theory. Because the bond energy of $\mathrm{NO}^{-}$is smaller, its $\mathrm{N}-\mathrm{O}$ bond is more easily broken and further oxidized to form final products (nitrates) by ROS in photocatalytic reactions on OV-BOC. However, the high $\mathrm{N}-\mathrm{O}$ bond energy of $\mathrm{NO}^{+}$and insufficient generation of ROS on BOC, lead to the incomplete oxidation of $\mathrm{NO}$ and generation of a toxic byproduct $\left(\mathrm{NO}_{2}\right)$.

In order to demonstrate in detail the enhancement of reactant (intermediate) activation via creation of oxygen vacancies via photocatalysis, DFT calculations were further carried out to analyze the adsorption energies on the active site (Fig. 8). Negative adsorption energy means the adsorption process releases heat, but the positive one is adverse. As shown in Fig. 8, the adsorption energy of $\mathrm{NO}$ and $\mathrm{NO}_{2}$ for both $\mathrm{BOC}$ and OV-BOC changes from negative to positive values, which indicates that the process needs external energy to be triggered. Apparently, the energy barrier preventing change of $\mathrm{NO}$ to $\mathrm{NO}_{2}$ for $\mathrm{OV}-\mathrm{BOC}$ $(0.6 \mathrm{eV})$ is lower than that of BOC $(1.5 \mathrm{eV})$. This suggests that the existence of oxygen vacancies could reduce the energy barrier and thus promote reactant activation under illumination by visible light. Moreover, the adsorption energy of the $\mathrm{NO}_{2} \rightarrow$ $\mathrm{NO}_{3}{ }^{-}$reaction for pristine $\mathrm{BOC}$ and $\mathrm{OV}-\mathrm{BOC}$ tends to increase,

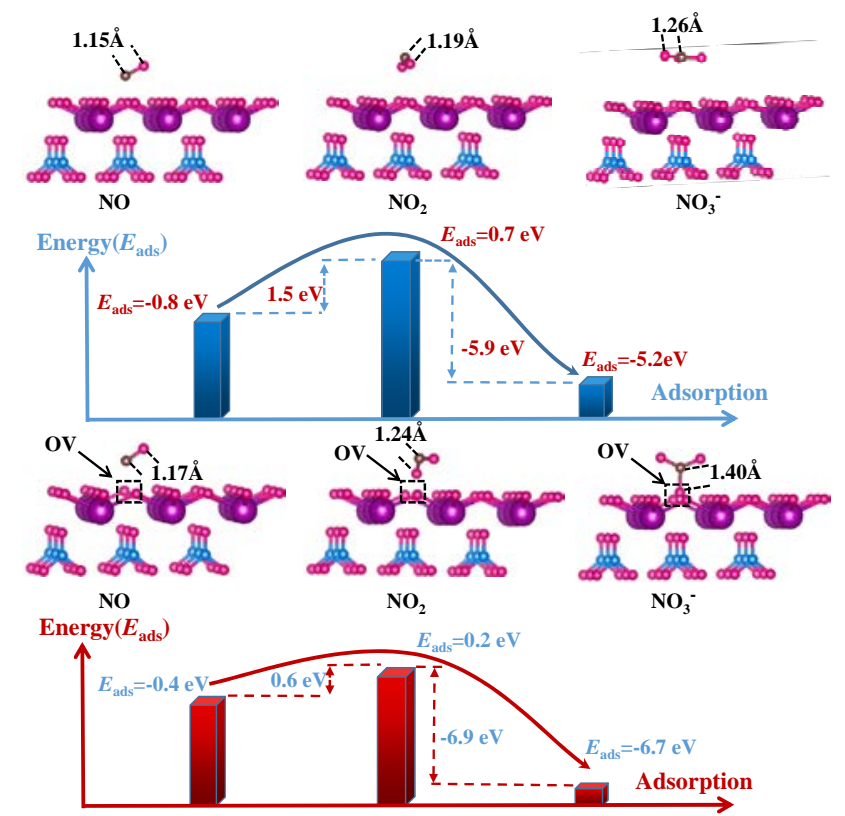

Fig. 8. DFT calculated adsorption energy and bond length of several major intermediate adsorption products (upward for BOC and downward for OV-BOC). which indicates the improved stability of $\mathrm{NO}_{3}^{-}$on $\mathrm{OV}-\mathrm{BOC}$. The energy of the exothermic reaction process is favorable. Interestingly, the exothermic quantity of this process for OV-BOC $(6.9 \mathrm{eV})$ is higher than that of pristine BOC (5.9 eV). This suggests that the $\mathrm{NO}_{2} \rightarrow \mathrm{NO}_{3}{ }^{-}$reaction of OV-BOC proceeds more easily because of the increased adsorption energy, which also corresponds well to the new nitrate bands during reaction on OV-BOC (Fig. 7b).

In comparison to that on the pristine $\mathrm{BOC}$, the $\mathrm{N}-\mathrm{O}$ bond length is apparently enlarged from 1.19 to $1.24 \AA$ during $\mathrm{NO}_{2}$ adsorption on OV-BOC, and from 1.26 to $1.40 \AA$ during $\mathrm{NO}_{3}{ }^{-}$ adsorption on OV-BOC. This results in a weakened Coulomb interaction of gas molecules on the catalyst surface, thus leading to change in the energy adsorbed from 0.7 to $0.2 \mathrm{eV}$ for $\mathrm{NO}_{2}$ and from -5.2 to $-6.7 \mathrm{eV}$ for $\mathrm{NO}_{3}$. Interestingly, the $\mathrm{N}-\mathrm{O}$ bond length in the NO adsorption of OV-BOC is slightly longer than that of BOC, which corresponds well to the appearance of $\mathrm{NO}^{+}$ on BOC and $\mathrm{NO}^{-}$on OV-BOC. This is because the $\mathrm{N}-\mathrm{O}$ bond energy of $\mathrm{NO}^{+}$is greater than that of $\mathrm{NO}^{-}$. These results imply that all reactants and intermediates can be more easily activated via the oxygen vacancies on OV-BOC. This is beneficial for the transformation of NO to target products rather than to toxic byproducts. Above all, the adsorption state and energy indicate that the strengthened activation of reactants and intermediates could promote the overall reaction efficiency and thus enormously boost the photocatalytic selectivity.

\section{Conclusions}

$\mathrm{Bi}_{2} \mathrm{O}_{2} \mathrm{CO}_{3}$ (BOC) nanosheets with oxygen vacancies were prepared successfully via a facile method. The OV-BOC displayed strengthened photocatalytic activity for NO removal compared to that of primary BOC under visible light irradiation. The oxygen vacancies could modify the band gap of BOC by forming defects at an intermediate level between the conduction band (CB) and valence band (VB). In addition, oxygen vacancies are beneficial for carrier separation and transportation, and for facilitating the activation of $\mathrm{O}_{2}$ and $\mathrm{H}_{2} \mathrm{O}$ molecules to generate abundant active species. More importantly, the oxygen vacancies can promote electron exchange between the reaction intermediates and the surface OV in OV-BOC, making them fully oxidized by the active radicals and transforming them into target products rather than toxic byproducts. This study provides a new approach for enhancing photocatalytic activity and selectivity, and also offers new insights for understanding the gas phase photocatalytic reaction mechanism.

\section{References}

[1] Z. J. Zhang, W. Z. Wang, M. Shang, W. Z. Yin, Catal. Commun., 2010, 11, 982-986.

[2] H. An, B. Lin, C. Xue, X. Q. Yan, Y. Z. Dai, J. J. Wei, G. D. Yang, Chin. J. Catal., 2018, 39, 654-663.

[3] C. H. Ao, S. C. Lee, J. Z. Yu, J. H. Xu, Appl. Catal. B, 2004, 54, 41-50.

[4] H. Wang, Y. Sun, G. Jiang, Y. Zhang, H. Huang, Z. Wu, S. C. Lee, F. Dong, Environ. Sci. Technol., 2018, 52, 1479-1487.

[5] R. B. Zhang, L. Gao, Q. H. Zhang, Chemosphere, 2004, 54, 405-411.

[6] W. Cui, J. Li, Y. Sun, H. Wang, G. Jiang, S. C. Lee, F. Dong, Appl. Catal. 


\section{Graphical Abstract}

Chin. J. Catal., 2019, 40: 620-630 doi: S1872-2067(19)63279-1

\section{Pivotal roles of artificial oxygen vacancies in enhancing} photocatalytic activity and selectivity on $\mathrm{Bi}_{2} \mathrm{O}_{2} \mathrm{CO}_{3}$ nanosheets

Hongjing Liu, Peng Chen, Xiaoya Yuan, Yuxin Zhang, Hongwei Huang, Li'ao Wang, Fan Dong*

Chongqing University;

University of Electronic Science and Technology of China;

Chongqing Technology and Business University;

China University of Geosciences

The illustration shows the band structure and photocatalytic NO removal process on OV-BOC. The oxygen vacancies in OV-BOC could reduce the width of the band gap, increase the charge separation efficiency, and activate the reactants to generate abundant reactive oxygen species (ROS) to participate in photocatalytic NO oxidation.

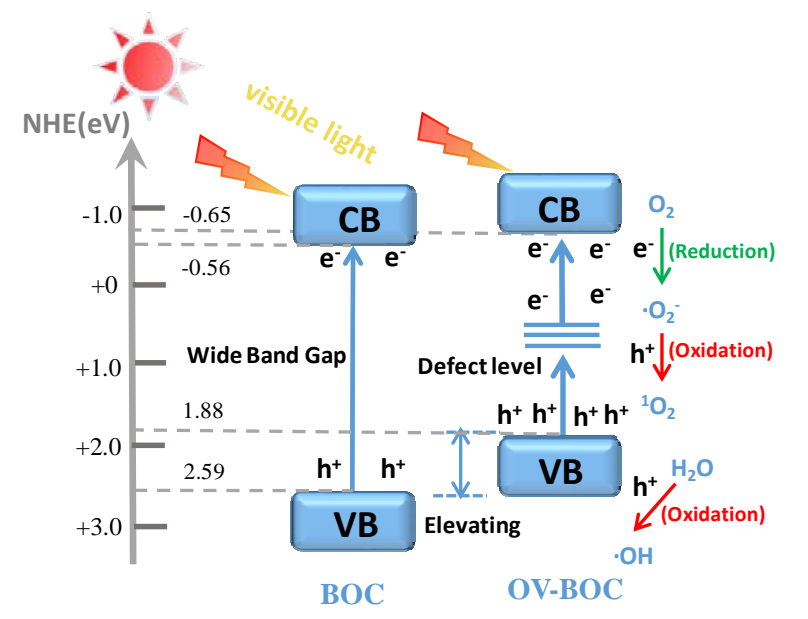

$B, \mathbf{2 0 1 8}, 237,938-946$.

[7] S. N. Habisreutinger, L. Schmidtmende, J. K. Stolarczyk, Angew. Chem. Int. Ed., 2013, 52, 7372-7408.

[8] J. Y. Li, X. A. Dong, Y. J. Sun, W. L. Cen, F. Dong, Appl. Catal. B, 2018, 226, 269-277.

[9] P. Zhang, T. Wang, X. Chang, J. Gong, Acc. Chem. Res., 2016, 49, 911-921.

[10] P. Chen, F. Dong, M. X. Ran, J. R. Li, Chin. J. Catal., 2018, 39, 619-629.

[11] C. C. Nguyen, D. T. Nguyen, T. O. Do, Appl. Catal. B, 2018, 226, 46-52.

[12] M. C. Long, L. H. Zheng, Chin. J. Catal., 2017, 38, 617-624.

[13] Z. L. Ni, W. D. Zhang, G. M. Jiang, X. P. Wang, Z. Z. Lu, Y. J. Sun, X. W. Li, Y. X. Zhang, F. Dong, Chin. J. Catal., 2017, 38, 1174-1183.

[14] P. Taylor, S. Sunder, V. J. Lopata, Can. J. Chem., 1984, 62, 2863-2873.

[15] R. Chen, M. H. So, J. Yang, F. Deng, C. M. Che, H. Sun., Chem. Commun., 2006, 2265-2267.

[16] Q. Zhang, S. Yuan, B. Xu, Y. Xu, K. Cao, Z. Jin, C. Qiu, M. Zhang, C. Su, T. Ohno, Catal. Today, 2018, 315, 184-193

[17] T. S. Natarajan, M. Thomas, K. Natarajan, H. C. Bajaj, R. J. Tayade, Chem. Eng. J., 2011, 169, 126-134.

[18] Y. C. Chen, K. I. Katsumata, Y. H. Chiu, K. Okada, N. Matsushita, Y. J. Hsu, Appl. Catal. A, 2015, 490, 1-9.

[19] Y. Zhang, D. Li, Y. Zhang, X. Zhou, S. Guo, L. Yang, J. Mater. Chem. A, 2014, 2, 8273-8280.

[20] N. Zhang, X. Li, H. Ye, S. Chen, H. Ju, D. Liu, Y. Lin, W. Ye, C. Wang, Q. Xu, J. Zhu, L. Song, J. Jiang, Y. Xiong, J. Am. Chem. Soc., 2016, 138, 8928-8935.

[21] Y. Wu, X. Ye, S. Zhang, S. Meng, X. Fu, X. Wang, X. Zhang, S. Chen, J. Catal., 2018, 359, 151-160.

[22] X. Jiao, Z. Chen, X. Li, Y. Sun, S. Gao, W. Yan, C. Wang, Q. Zhang, Y. Lin, Y. Luo, Y. Xie, J. Am. Chem. Soc., 2017, 139, 7586-7594.

[23] H. Wang, X. S. Sun, D. D. Li, X. D. Zhang, S. C. Chen, W. Shao, Y. P. Tian, Y. Xie, J. Am. Chem. Soc., 2017,139, 2468-2473.

[24] M. Y. Xing, Y. Zhou, C. Y. Dong, L. J. Cai, L. X. Zeng, B. Shen, L. H. Pan, C. C. Dong, Y. Chai, J. L. Zhang, Y. D. Yin, Nano Lett., 2018, 18, 3384-3390.
[25] H. Z. Fang, X. Hui, G. L. Chen, R. Öttking, Y. H. Liu, J. A. Schaefer, Z. K. Liu, Comput. Mater. Sci., 2008, 43 1123-1129

[26] Z. Zhang, L. Zhou, P. E. Wigen, K. Ounadjela, Phys. Rev. B, 1994, 50, 6094-6112.

[27] J. T. Arantes, G. M. Dalpian, A. Fazzio, Phys. Rev. B, 2008, 78, 1436-1446

[28] Y. Zhou, H. Wang, M. Sheng, Q. Zhang, Z. Zhao, Y. Lin, H. Liu, G. R. Patzke, Sens. Actuators B, 2013, 188, 1312-1318.

[29] J. Jiang, L. Zhang, H. Li, W. He, J. J. Yin, Nanoscale, 2013, 5, 10573-10581.

[30] C. Wang, C. Shao, Y. Liu, L. Zhang, Scr. Mater., 2008, 59, 332-335.

[31] H. Li, T. Hu, N. Du, R. Zhang, J. Liu, W. Hou, Appl. Catal. B, 2016, 187, 342-349.

[32] H. Huang, J. Wang, F. Dong, Y. Guo, N. Tian, Y. Zhang, T. Zhang, Cryst. Growth. Des., 2015, 15, 534-537.

[33] F. Dong, Y. Sun, M. Fu, Z. Wu, S. C. Lee, J. Hazard. Mater., 2012, 219-220, 26-34.

[34] X. A. Dong, W. Zhang, Y. Sun, J. Li, W. Cen, Z. Cui, H. Huang, F. Dong, J. Catal., 2018, 357, 41-50.

[35] Z. Zhao, Y. Zhou, F. Wang, K. Zhang, S. Yu, K. Cao, ACS Appl. Mater. Interfaces, 2015, 7, 730-737.

[36] X. Feng, W. Zhang, Y. Sun, H. Huang, F. Dong, Environ. Sci. Nano, 2017, 4, 604-612.

[37] Y. Bai, L. Ye, T. Chen, L. Wang, X. Shi, X. Zhang, D. Chen, ACS Appl. Mater. Interfaces, 2016, 8, 27661-27668.

[38] F. Dong, A. Zheng, Y. Sun, M. Fu, B. Jiang, W. K. Ho, S. C. Lee, Z. Wu, CrystEngComm, 2012, 14, 3534-3544.

[39] X. Dong, W. Zhang, W. Cui, Y. Sun, H. Huang, Z. Wu, F. Dong, Catal. Sci. Technol., 2017, 7, 1324-1332.

[40] F. Dong, T. Xiong, Y. Sun, H. Huang, Z. Wu, J. Mater. Chem. A, 2015, 3, 18466-18474.

[41] A. Folli, J. Z. Bloh, D. E. MacPhee, J. Electroanal. Chem., 2016, 780, 367-372.

[42] X. Jin, L. Ye, H. Wang, Y. Su, H. Xie, Z. Zhong, H. Zhang, Appl. Catal. B, 2015, 165, 668-675.

[43] K. Dasuri, L. Zhang, J. N. Keller, Free Radic. Biol. Med., 2013, 62, 170-185.

[44] T. Daimon, Y. Nosaka, J. Phys. Chem. C, 2007, 111, 4420-4424. 
[45] V. Diesen, M. Jonsson, J. Phys. Chem. C, 2014, 118, 10083-10087.

[46] K. Komaguchi, T. Maruoka, H. Nakano, I. Imae, Y. Ooyama, Y. Harima, J. Phys. Chem. C, 2010, 114, 1240-1245.

[47] M. Kantcheva, A. S. Vakkasoglu, J. Catal., 2004, 223, 352-363.

[48] H. Hu, S. Cai, H. Li, L. Huang, L. Shi, D. Zhang, J. Phys. Chem. C, 2015, 119, 22924-22933.

[49] K. Hadjiivanov, V. Avreyska, D. Klissurski, T. Marinova, Langmuir, 2002, 18, 1619-1625.
[50] M. Kantcheva, J. Catal., 2001, 204, 479-494.

[51] K. I. Hadjiivanov, Catal. Rev.-Sci. Eng., 2000, 42, 71-144.

[52] K. Hadjiivanov, H. Knözinger, Phys. Chem. Chem. Phys., 2000, 2, 2803-2806.

[53] G. Ramis, G. Busca, V. Lorenzelli, P. Forzatti, Appl. Catal., 1990, 64, 243-257.

[54] W. Zhang, X. Dong, Y. Liang, Y. Sun, F. Dong. Appl. Surf. Sci., 2018, 455, 236-243.

\title{
人工氧缺陷对提高 $\mathrm{Bi}_{2} \mathrm{O}_{2} \mathrm{CO}_{3}$ 纳米片光催化活性和选择性的关键作用
}

\author{
刘红婧 ${ }^{\mathrm{a}}$, 陈 鹏, 袁小亚 ${ }^{\mathrm{d}}$, 张育新 ${ }^{\mathrm{e}}$, 黄洪伟 ${ }^{\mathrm{f}}$, 王里奥 ${ }^{\mathrm{a}}$, 董 帆, ${ }^{\mathrm{b}, *}$ \\ a重庆大学煤矿灾害动力学与控制国家重点实验室, 资源及环境科学学院, 重庆400044 \\ ${ }^{\mathrm{b}}$ 电子科技大学基础与前沿科学研究院, 环境科学与技术研究中心, 四川成都611731 \\ ${ }^{\mathrm{c}}$ 重庆工商大学环境与资源学院, 催化与环境新材料重庆市重点实验室, 重庆 400067 \\ $\mathrm{d}^{\mathrm{i}}$ 庆交通大学材料科学与工程学院, 重庆 400074 \\ ${ }^{\mathrm{e}}$ 重庆大学材料科学与工程学院, 机械传动国家重点实验室, 重庆 400044

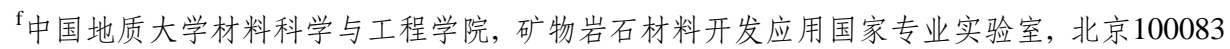

\begin{abstract}
摘要: 碳酸氧铋 $\left(\mathrm{Bi}_{2} \mathrm{O}_{2} \mathrm{CO}_{3}, \mathrm{BOC}\right)$ 是一种新兴的半导体光催化剂. 然而, 纯BOC具有较强的紫外光吸收能力和较高的载流 子复合率, 因而其光催化效率较低. 本研究通过添加 $\mathrm{NaBH}_{4}$ 在 $\mathrm{BOC}$ 表面引入氧缺陷(标记为OV-BOC), 以拓宽光吸收范围, 提高电荷分离效率. 结果表明, $\mathrm{NaBH}_{4}$ 的加入改变了 $\mathrm{BOC}$ 的表面结构, 产生了更多的氧缺陷作为活化反应物的反应位点, 使 光催化净化NO的去除率由BOC的 $10.0 \%$ 提高到OV-BOC的 $50.2 \%$. XRD、XPS和EPR的测定结果证明了含有氧缺陷的正方 晶系BOC的成功合成. SEM和TEM表征发现OV-BOC为纳米片状结构, 并且其表面的确因缺陷而形成了晶格条纹的变化. UV-vis DRS、Mott-Schottky和禁带宽度计算结果发现BOC中的氧缺陷可以减小禁带宽度, 而PL和SPV的测定结果表明氧缺 陷也促进了电荷转移. 根据ESR 谱和DFT计算结果, OV-BOC的所有活性氧信号强度大大超过BOC, 进一步证明氧缺陷可 以促进载流子的生成和运输. 此外, OV-BOC的 $-\mathrm{OH}$ 信号强度超过 $\mathrm{BOC}$, 说明氧缺陷可以驱动电子/空穴的分离, 从而促进 - $\mathrm{OH}$ 的产生. 因此, $\mathrm{O}_{2}$ 和 $\mathrm{H}_{2} \mathrm{O}$ 分子的活化被促进, 从而产生更多的活性氧参与光催化反应并极大地提高了 $\mathrm{NO}$ 的去除效率. 另外, 利用原位红外光谱动态监测了光催化氧化NO反应的中间产物的演化过程. 结合原位红外光谱和DFT的结果表明, 氧 缺陷能促进OV-BOC中间产物和表面氧缺陷之间的电子交换, 使反应物更容易被活性自由基氧化, 这有利于NO转化为目 标产物从而抑制毒副产物的生成. 该研究为提高光催化剂活性和选择性提供了新的途径, 也为理解气相光催化反应机理 提供了新的思路.
\end{abstract}

关键词：碳酸氧铋; 氧缺陷; 可见光催化; 反应物活化; 光催化机理

收稿日期: 2018-12-12. 接受日期: 2018-12-14. 出版日期: 2019-05-05.

*通讯联系人. 电话/传真: (023)62769785; 电子信箱: dfctbu@126.com

基金来源：国家重点研发计划(2016YFC02047); 国家自然科学基金(21822601，21777011，21501016); 重庆市研究生创新基金 (CYS18019); 重庆市高校创新团队(CXTDG201602014); 重庆市自然科学基金(cstc2017jcyjBX0052); 国家“万人计划”青年拔尖人 才项目.

本文的电子版全文由Elsevier出版社在ScienceDirect上出版(http://www.sciencedirect.com/science/journal/18722067). 